\title{
Summary of the Monograph of F. I. Samedova "The Application of Supercritical Fluids in Petroleum and Oil Fractions Refining"
}

\author{
F. I. Samedova, R. Z. Gasanova, A. M. Kasumova, S. Y. Rashidova, A. D. Kuliyev, B. M. Aliyev, \\ N. F. Kafarova \\ Institute of Petrochemical Processes Named after Academician Y. H. Mamedaliyev, ANAS, Baku, Azerbaijan \\ Email: lab.21@mail.ru
}

Received 25 April 2015; accepted 26 June 2015; published 30 June 2015

Copyright (C) 2015 by authors and Scientific Research Publishing Inc. This work is licensed under the Creative Commons Attribution International License (CC BY). http://creativecommons.org/licenses/by/4.0/ (c) (i) Open Access

\section{Abstract}

In the monograph of F. I. Samedova "The application of supercritical fluids in petroleum refining and oil fractions" (Baku, 2014) the results of the use of supercritical fluids in petroleum refining and petroleum products are presented. The investigations were made under the guidance of the corresponding member of the Azerbaijan National Academy of Science, professor F. I. Samedova and representatives of the scientific school she has established: Doctor of Technical Sciences R. Z. Gasanova, Ph.D. A. M. Kasumova, Ph.D. S. Y. Rashidova and N. F. Kafarova, as well as with representatives of the spectral laboratory Ph.D. A. D. Kuliyev and Ph.D. B. M. Aliyev. Scientific editors of the monograph are academics M. I. Rustamov and V. M. Abbasov. The recent advances in term of the possible applications of supercritical extraction processes in the field of oil refining and oil fractions are shown. The analysis of the economic efficiency of supercritical extraction processes using $\mathrm{SC} \mathrm{CO}_{2}$ is carried out. The scheme of the pilot plant at the Experimental Plant of the Institute of Petrochemical Processes of Azerbaijan National Academy of Sciences (IPCP of ANAS) is described. The monograph [1] is intended for researchers, graduate students, engineers and graduate students engaged in the development and introduction of new energy-saving and environmentally friendly technologies for oil refining and oil fractions. In order to find the ways to create energy-efficient, environmentally-friendly technologies in 1970 the use of supercritical fluids as solvents in cleaning processes, extraction, separation and fractionation are proposed. This approach can lead to the creation of environmentally friendly processes in the food, perfumery, pharmaceutical, oil, coal processing industry and in the field of polymer processing. Considering the need of creation of environmentally friendly and energy-saving technologies in the oil refining industries, in 2000 IPCP of ANAS began the research on the intensification of processes used in the oil industry-oil refining and heavy fractions of water, salts and solids, high molecular heteroatom- 
ic compounds: resinous-asphaltene substances including the metals using a supercritical fluid. The monograph highlights the results of studies on the use of supercritical fluid $\mathrm{SC}^{\mathrm{CO}_{2}}$ emissions from petroleum refining and oil fractions with a view to their intensification and ecological rehabilitation of the environment.

\section{Keywords}

\section{Supercritical Carbon Dioxide, Oil Refining, Oil Fractions, Deasphalting, Demetallization}

\section{The Main Methods and Results Reflected in the Book}

\section{Development of the Method for Determining the Content of Asphaltenes in Oil}

An important feature is the selectivity of the solvent, the ability to extract unwanted components of the feed. Necessary selectivity of the process is usually provided by varying the temperature and pressure of the system, which is controlled by the process of supercritical extraction [2]-[4].

Now the using of carbon dioxide $\left(\mathrm{CO}_{2}\right)$ is in the focus because of its relatively low critical parameters $\left(\mathrm{T}_{\mathrm{cr}}{ }^{-}\right.$ $37^{\circ} \mathrm{C}$ ), light reconditioning, high volatility, non-incendive, cheapness and availability. It should be noticed that the main directions of the use of supercritical solvent in the process of refining and petrochemical industries were determined since the beginning of 2000. This process is used for deasphalting of heavy residues, because it makes possible the appreciable reduction of the ratio of solvent to remove of the raw materials and their components selectively, thereby improving the efficiency of the processes.

Azerbaijan supercritical technologies were first used in the process of extracting oil from oil-bearing rocks and soils, under the leadership of A. H. Mirzajanzadeh and his colleagues [5]-[10].

More research in this direction started in the 90s of the last century in the Kazan University [3] [11], and continue to this day [12].

The monograph provides the properties of supercritical fluids, new ways of defining asphaltenes in oil and heavy residues deasphalting developed under the guidance and with the participation of the author of the monograph and demetallization of heavy oil residues, dehydration and desalting using $\mathrm{SC} \mathrm{CO}_{2}$, increasing the solvent power of supercritical fluid by adding of cosolvents-cleaning oil fraction, deasphalting of residual oil fraction (tar), the allocation of oil from the tar sands of Azerbaijan.

The main disadvantages of the most common and well-known methods of determining asphaltene (method of Golde and standard methods) are the use of large amounts of solvent ( 40 fold) to coagulate asphaltenes dilution of the test sample (5 - $10 \mathrm{~g}$ ) of mineral oil, a suitable solvent, the duration of analysis and blurred separation.

The energy needs of the process under supercritical $\mathrm{CO}_{2}$ are significantly less than that in conventional processes using a hydrocarbon extraction solvent.

The preparative method for the determination of asphaltenes in crude oil and heavy oil residues using the unique properties of supercritical $\mathrm{CO}_{2}$ is created and patented in IPCP of ANAS [13].

New developed method allows the product to increase from 5 - 10 to $100 \mathrm{~g}$; the amount of the solvent reduces its dilution from 40 to 1 - 2 fold to improve clarity of asphaltene precipitation, and to reduce the duration of the analysis in comparison with the known number of sample test [14].

The proposed method can be used to improve existing standards-ГОСТ 1185-85 and its application is used for the quantitative determination of asphaltenes in petroleum and petroleum products, and also to highlight sufficient quantity to study their composition and properties.

\section{Deasphalting and Demetallization of Heavy Oil Residues}

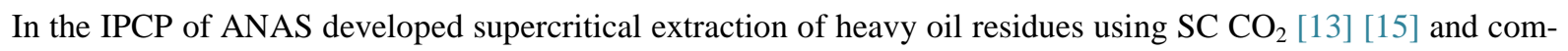
pared with the Doben process, which is widely used for the preparation of heavy oil residues for further processing.

The comparative data from the known and the proposed method are given in Table 1 [15].

Figure 1 is a scheme of the laboratory setup for deasphalting of oil and heavy residues with $\mathrm{CO}_{2}$ in its super- 
Table 1. Deasphalting of tar with proposed process using $\mathrm{SC} \mathrm{CO}_{2}$ and the existing industrial Doben process.

\begin{tabular}{ccc}
\hline & Proposed & Existing \\
\hline The ratio of the hydrocarbon solvent ${ }^{*}$ to the feed & $1: 1$ & $(3.5 / 5.0): 1$ \\
Extraction temperature, ${ }^{\circ} \mathrm{C}$ & $70-90$ & $150-160$ \\
Heat of the solution in an oven deasphalting, ${ }^{\circ} \mathrm{C}$ & Absence & $270-280$ \\
Regeneration of the solvent & By reducing the pressure & $\begin{array}{c}\text { Two-stage regeneration with a special } \\
\text { distillation unit using water vapor }\end{array}$ \\
The degree of asphaltenes' separation & High & Low \\
DAO yield, \% by weight. for raw materials & 95.5 & $85-88$ \\
\hline
\end{tabular}

${ }^{*}$ In both cases we use the same hydrocarbon solvent.

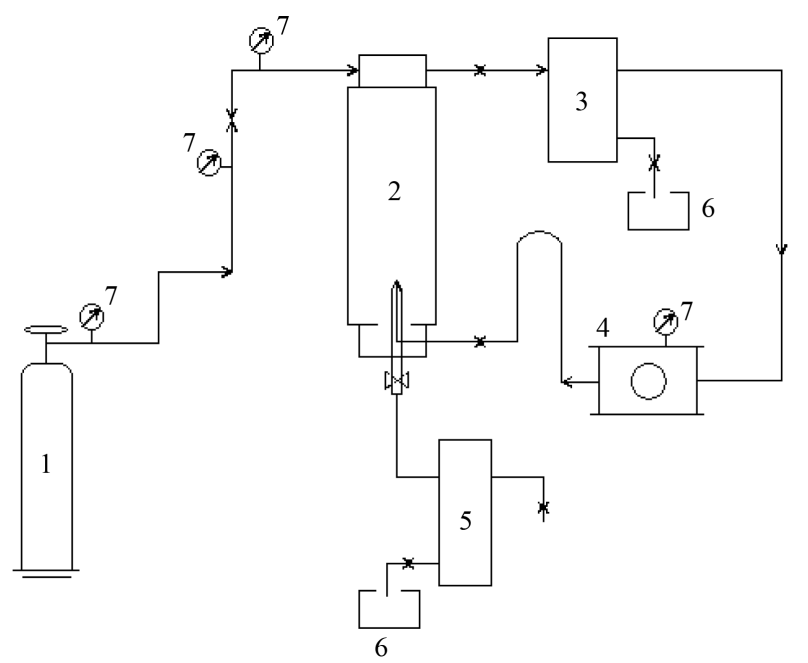

Figure 1. The scheme of laboratory setup for deasphalting of oil and heavy residues with $\mathrm{CO}_{2}$ in its supercritical conditions. 1-carbon dioxide cylinders; 2-the extractor; 3-gas filter; 4-compressor; 5-separator; 6-container of products; 7 pressure gauges.

critical conditions. The characteristics of heavy oil residues before and after deasphalting using $\mathrm{CO}_{2}$ in its supercritical and microelement composition are shown in Table 2 and Table 3.

The studies of microelement composition of the residue of deasphalted oil (tar) showed that they significantly (up to $30 \%-50 \%$ wt.) enriched with metals, i.e. raw material is cleaned of metals and asphaltenes which are not detected in the feed (Table 4) [13]-[16].

To optimize the parameters of the process the effect of dilution of raw material with hydrocarbon solvent, pressure and temperature on the results of cleaning of the mixture of low paraffinic oils and its heavy residue are studied [16]-[18].

\section{Dehydration and Desalting of Oil}

The preparation of oil for processing is an important step in the refining technologies. Therefore, not only cleaning of oil from the asphaltenes and metals, as well as water, salts, solids is important.

The water content of the oil transported through pipelines, is up to $1 \%$, and in arriving at the refineries it should be no more than $0.5 \%$ [19].

For the study the mixtures of Neft Dashlary, Shirvan and Surakhany oils, processed at the refinery named after Heydar Aliyev were used. The data of content of oils in mixtures I, II, III are shown in Table 4.

In Figure 2 the scheme of an oil extraction of undesired components with $\mathrm{SC}^{-\mathrm{CO}_{2}}$ is shown.

The results of the comparison of existing and proposed $\left(\mathrm{SC}-\mathrm{CO}_{2}\right)$ methods of dehydration and desalting are shown in Table 5. 
Table 2. The results of deasphalting of ordinary and heavy oils using $\mathrm{CO}_{2}$ in its supercritical conditions.

\begin{tabular}{|c|c|c|c|c|c|c|c|c|c|c|}
\hline & \multirow{4}{*}{ Name } & \multirow{4}{*}{$\begin{array}{l}\text { Density at } \\
20^{\circ} \mathrm{C}, \mathrm{kg} / \mathrm{m}^{3}\end{array}$} & \multirow{4}{*}{$\begin{array}{c}\text { Viscosity } \\
\text { at } 50^{\circ} \mathrm{C} \text {, } \\
\mathrm{mm}^{2} / \mathrm{s}\end{array}$} & \multicolumn{2}{|c|}{ Temperature of, ${ }^{\circ} \mathrm{C}$} & \multirow{4}{*}{ Coking, \% } & \multicolumn{4}{|c|}{$\begin{array}{c}\text { Yield in \% by weight of asphaltenes, } \\
\text { with the method: }\end{array}$} \\
\hline & & & & \multirow{3}{*}{ Freezing } & \multirow{3}{*}{ Flash } & & \multicolumn{2}{|c|}{ Proposed } & \multicolumn{2}{|c|}{ Existing } \\
\hline & & & & & & & Before & After & Before & After \\
\hline & & & & & & & The ex & action & The ex & action \\
\hline \multirow[b]{2}{*}{ Oil } & Initial & 865.9 & 7.11 & -10 & 5 & 1.91 & - & & - & \\
\hline & $\begin{array}{l}\text { The same, after } \\
\text { deasphalting }\end{array}$ & 859.0 & 6.33 & -10 & 5 & 0.88 & 1.50 & 1.07 & 0.87 & 0.58 \\
\hline \multirow{3}{*}{ Masut $\left.^{*}\right)$} & Initial & 909.5 & 43.22 & +8 & 146 & 3.51 & - & - & - & \\
\hline & $\begin{array}{l}\text { The same, diluted } \\
\text { in n-heptane }\end{array}$ & 783.0 & 1.82 & - & - & - & - & & - & \\
\hline & $\begin{array}{l}\text { The same, after } \\
\text { deasphalting }\end{array}$ & 907.4 & 42.0 & +6 & 148 & 3.30 & 3.10 & 2.57 & 1.0 & 0.79 \\
\hline \multirow{3}{*}{$\left.\operatorname{Tar}^{*}\right)$} & Initial & 947.3 & $181.1^{* *)}$ & 49 & 280 & 4.67 & - & & - & \\
\hline & $\begin{array}{l}\text { The same, diluted in } \\
\text { n-heptane }\end{array}$ & 787.0 & 4.19 & - & - & - & - & & - & \\
\hline & $\begin{array}{l}\text { The same, after } \\
\text { deasphalting }\end{array}$ & 940.3 & $105.6^{* *)}$ & 48 & 280 & 4.10 & 4.50 & 3.96 & 1.46 & 0.89 \\
\hline
\end{tabular}

${ }^{*}$ The yields of oil and tar, respectively, $60.2 \%$ and $30.4 \%$ for oil. ${ }^{* *}$ At $100^{\circ} \mathrm{C}$.

Table 3. Trace element composition of raw materials and asphaltite, ppm.

\begin{tabular}{|c|c|c|c|c|}
\hline Name & Initial oil & Asphalt derived from oil & Initial tar & Asphalt derived from tar \\
\hline $\mathrm{Al}$ & 56.84 & 78.6 & 70.52 & 110.0 \\
\hline $\mathrm{Ba}$ & 2.3 & 4.96 & 8.77 & 13.3 \\
\hline $\mathrm{Cd}$ & 0.19 & 0.63 & 0.42 & 0.65 \\
\hline $\mathrm{Cr}$ & 20.39 & 25.09 & 25.0 & 89.2 \\
\hline $\mathrm{Cu}$ & 11.79 & 19.2 & 12.74 & 24.0 \\
\hline $\mathrm{Fe}$ & 8.50 & 243.6 & 181.08 & 703.7 \\
\hline $\mathrm{K}$ & 44.8 & 52.2 & 54.08 & 125.6 \\
\hline Mg & 0.1 & 201.0 & - & 214.8 \\
\hline Mn & 2.82 & 4.4 & 3.28 & 22.3 \\
\hline $\mathrm{Na}$ & 335.6 & 890.2 & 120.6 & 839.6 \\
\hline $\mathrm{Ni}$ & 10.66 & 24.4 & 18.0 & 136.16 \\
\hline Pt & - & - & - & few \\
\hline $\mathrm{Pb}$ & 1.61 & $<8.0$ & 2.99 & 5.22 \\
\hline Sn & - & $<4.89$ & - & few \\
\hline $\mathrm{V}$ & 0.22 & 0.39 & 0.63 & 2.17 \\
\hline $\mathrm{Zn}$ & 3.7 & 5.6 & 37.47 & 46.71 \\
\hline Se & - & 8.57 & - & - \\
\hline Co & 1.2 & 1.29 & - & - \\
\hline $\mathrm{Sb}$ & - & - & - & few \\
\hline $\mathrm{Au}$ & - & - & - & few \\
\hline As & - & - & - & 2.89 \\
\hline $\mathrm{Hg}$ & - & - & - & 10.96 \\
\hline
\end{tabular}


Table 4. The mixtures of refined crude oils.

\begin{tabular}{|c|c|c|c|c|c|c|}
\hline \multirow{3}{*}{ Oil mixture } & \multicolumn{6}{|c|}{ Oil and its content in the mixture } \\
\hline & \multicolumn{2}{|c|}{ Neft Dashlary } & \multicolumn{2}{|c|}{ Shirvan } & \multicolumn{2}{|c|}{ Surakhany } \\
\hline & $\mathrm{t}$ & $\%$ & $\mathrm{t}$ & $\%$ & $\mathrm{t}$ & $\%$ \\
\hline I & 6506 & 42.99 & 5103 & 33.76 & 3522 & 23.28 \\
\hline II & 5005 & 37.79 & 5027 & 37.95 & 3216 & 24.26 \\
\hline III & 7246 & 50.55 & 5058 & 35.28 & 2031 & 14.17 \\
\hline
\end{tabular}

Table 5. The comparison of existing and proposed $\left(\mathrm{SC} \mathrm{CO}_{2}\right)$ methods of dehydration and desalting.

\begin{tabular}{|c|c|c|}
\hline Indicators & Proposed & Existing \\
\hline The ratio of solvent to raw materials & $1: 1$ & Absence \\
\hline Temperature of dehydration, ${ }^{\circ} \mathrm{C}$ & $40-45$ & $110-120$ \\
\hline \multicolumn{3}{|l|}{ Contents: } \\
\hline Water in oil in AVT, \% & Absence & $0.1-0.15$ \\
\hline salts, mg/l & Absence & $3-10$ \\
\hline Consumption of demulsifier, g/t & Absence & $8-30$ \\
\hline The economic effect of the processing $6.0 \mathrm{mln}$. $\mathrm{t}$ of oil, mln. manat & 2.3 & - \\
\hline Operating costs, mln. manat per year & 50.679 & 55.626 \\
\hline
\end{tabular}

\section{Increasing of the Solvent Power of Supercritical Fluids by the Addition of Co-Solvents}

Supercritical fluid extraction process is carried out in the presence of $\mathrm{CO}_{2}$ and a co-solvent-acetone, n-heptane, toluene or mixtures of toluene and n-heptane with acetone and ethyl alcohol. The extraction process is con-

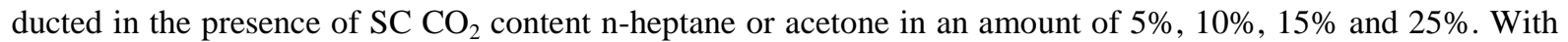
increasing the concentration of acetone from $5 \%$ to $25 \%$, the viscosity of oil at $20^{\circ} \mathrm{C}$ rises from 17.33 to 21.28 $\mathrm{mm}^{2} / \mathrm{s}$, its pour point changes from minus $41^{\circ} \mathrm{C}$ to minus $31^{\circ} \mathrm{C}$, coking increases from $1.74 \%$ to $2.33 \%$.

By proceeding SC $\mathrm{CO}_{2}$ extraction with heptane positive results in reducing the pour point of the oil up to minus 60 - minus $62^{\circ} \mathrm{C}$ compared to minus $52^{\circ} \mathrm{C}$ at the feed oil. Coking ability is also reduced from $1.69 \%$ to

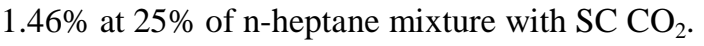

\section{The Purification of the Oil Fraction with a Two-Phase System Using $\mathrm{SC} \mathrm{CO}_{2}+$ Co-Solvent}

There are ways to increase the effectiveness of solvents for cleaning oil fractions using paired solvents.

The influence of the pair of solvents on the selective treatment processes, deasphalting; influence of components of the solvent pair-one of the solvents should dissolve the contaminants, other cleansing oil, shows the effect of polar and nonpolar nature of the components in the mixture of solvents when using paired solvents, and changing the solvent and selective solvent capacity with temperature change [20]-[23]. For each system, the selection of the optimal temperature and the ratio of its components are conducted.

The book also contains the results of studies of selective purification of oil fractions with medium and high viscosity with viscosity of $7-8 \mathrm{~mm}^{2} / \mathrm{s}$ at $100^{\circ} \mathrm{C}$ based on the two-phase solvent $\mathrm{N}$-methylpyrrolidone and furfurol with carbon dioxide in supercritical conditions.

For selective treatment of feedstock we used medium viscosity oil fraction from a mixture low-paraffinic Azerbaijani oil, processed at "Azerneftyag" refinery. It is found that the oil fraction has a low viscosity index (63.3), dark color, high acid number $-0.32 \mathrm{mg} \mathrm{KOH} / \mathrm{g}$. 


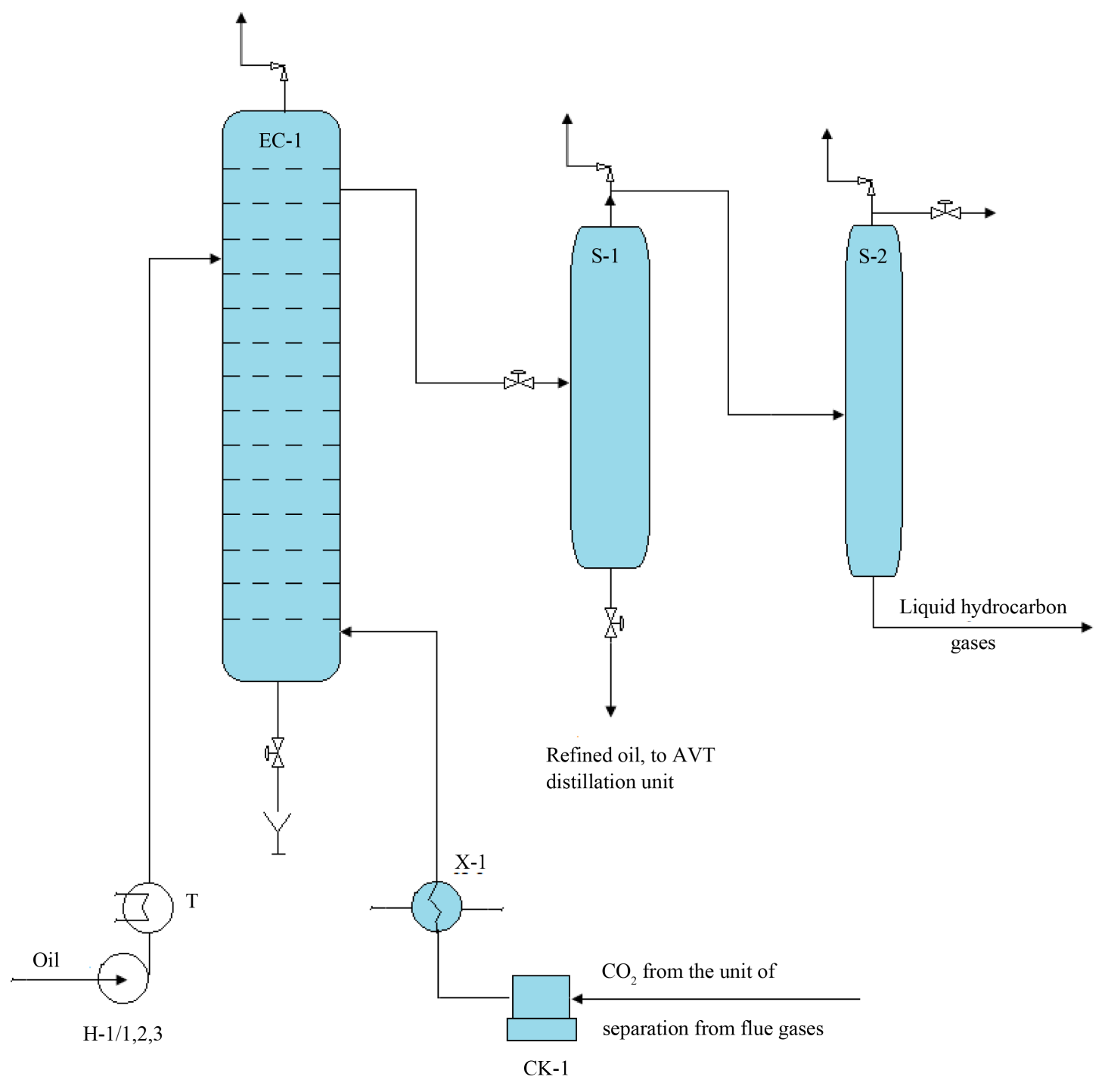

Figure 2. The circuit of extraction of undesirable components from the oil with $\mathrm{SC}^{\mathrm{CO}}$. $\mathrm{CK}-1-\mathrm{CO}_{2}$ compressor; EC-1-extraction column; S-1, S-2-separators; H-1/1,2,3-oil supply pump; T-heat exchanger heating oil; X-1-refrigerator.

The cleaning in the two-phase system (pair solvent) was carried out on the pilot installation of supercritical extraction of the Institute.

The possibility of achieving a high degree of purification with a lower ratio of oil using two-phase solvent fraction $\mathrm{SC} \mathrm{CO}_{2}+$ co-solvent at a lower temperature and less is shown.

\section{The Process of Extraction of Oil from Bituminous Sands of Azerbaijan Using Supercritical Extraction Process}

With the continuous depletion of conventional oil, the content of so-called bituminous sands becomes very important.

Deposits of oil in bituminous rocks exist in Girmaky rocks in Azerbaijan.

Earlier IPCP conducted the pilot projects to obtain oil from the Girmaky sands by thermal extraction in highperformance machines [24].

The alternative to a large number of hydrocarbons (methane, propane, etc., and mixtures thereof), introduced for the extraction of carbon dioxide may serve as the supercritical state. 
The use of supercritical extraction processes in oil production and refining in order to increase oil recovery is one of the most pressing problems; its solution allows you to create high-waste technologies to maximize oil recovery.

With increasing pressure and temperature of $\mathrm{CO}_{2}$ into the liquid phase, and then at a pressure higher than 7.3 MPa is converted into a supercritical (SC) fluid, where its properties are shown as both gas and liquid.

The fluid has a high penetrating ability and solubility, which is higher than that of traditional solvents [25].

$\mathrm{SC} \mathrm{CO}_{2}$, pumped into the formation, dissolves in the oil by its own expansion and liquefaction oil extracts.

In IPCP of ANAS and AzNIPI the investigations of separation of oil from bituminous minerals, study of its properties and further processing of the selected oil were carried out [26]-[28]. Oil extracted from the oil-saturated sand with the relaxation method had a density at $20^{\circ} \mathrm{C}$ of $1143.9 \mathrm{~kg} / \mathrm{m}^{3}$, viscosity at $100^{\circ} \mathrm{C} \mathrm{of} 9.5 \mathrm{~mm} / \mathrm{s}$. The composition and properties of the oil, the possibility of obtaining oils and fuels are given in [26]. The methods of refining of oil from oil-saturated sand through its catalytic treatment with $\alpha$-olefins and hydrotreating oil-saturated sands without prior isolation of the organic part (oil), occur simultaneously with upgrading and separation of oil from the sand [27].

Along with the studies, which are described above, the separation of oil and bitumen from the oil-saturated ground with the mixture of carbon dioxide and supercritical solvents (heptane and the mixture of alcohol and benzene) is conducted. The proposed method ensures the effective allocation of oil with less solvent consumption. The advantages of this method are its low cost, high safety, easy separation of carbon dioxide from the crude oil. Experiments were conducted in a pilot plant of the Institute for supercritical extraction.

The oil from the oil-saturated ground of Mashtaga deposits is separated with $\mathrm{SC} \mathrm{CO}_{2}$ and heptanes (1:1); they were fed to the reactor at a temperature of $40^{\circ} \mathrm{C}$, the pressure of $8 \mathrm{MPa}$ and carbon dioxide was supplied for 2 hours. After the experiment was complete and the obtained sludge was separated from the ground and oil heptane solution, the reactor was charged with the ground and mixture of alcohol and benzene (1:4) at a ratio of 100 $\mathrm{ml}$ newly supplied carbon dioxide (1:1) (T-40 $\left.{ }^{\circ} \mathrm{C}, \mathrm{P}-8 \mathrm{MPa}\right)$ for 2 hours, extracted resinous-asphaltene substances (RAS). Yields after SC-extraction from bituminous sands are shown in Table 6. The data in Table 6 shows that oil can be isolated from bituminous ground in an amount of 99\% of capacity, including oil and RAS $66.7 \%$ $33.2 \%$ by weight using a solvent $+\mathrm{SC} \mathrm{CO}_{2}$. The process of isolation oil using only $\mathrm{SC} \mathrm{CO}_{2}$ without solvent hardly occurs.

After distillation with heptane and alcohol-benzene, the output of oil and resin-asphaltene substances (RAS) is determined.

The application of $\mathrm{SC} \mathrm{CO}_{2}$ during the extraction of oil from bituminous sands allows reducing the amount of solvents more than two times, as well as fully extraction of RAS containing saturated hydrocarbons with a high

Table 6. Yields of RAS and oil extracted from bituminous ground with different ways.

\begin{tabular}{|c|c|}
\hline Oil extraction & Yield, \% \\
\hline \multicolumn{2}{|l|}{ 1) With solvents (heptane, benzine), in $1: 2$ ratio, $\mathrm{T}-80^{\circ} \mathrm{C}, \%$ : } \\
\hline Organic part of bituminous ground, including: & 99.0 \\
\hline Oil & 88.0 \\
\hline RAS (alcohol-benzene 1:2) & 11.0 \\
\hline \multicolumn{2}{|c|}{ 2) Hydrogenation of the oil in the ground (with ground as catalyst, $\left.\mathrm{T}-340^{\circ} \mathrm{C}-360^{\circ} \mathrm{C}, \mathrm{H}_{2}-600 \mathrm{l} / \mathrm{l}\right), \%$ : } \\
\hline Organic part of bituminous ground, including: & 98.0 \\
\hline Oil & 94.0 \\
\hline RAS & 4.0 \\
\hline \multicolumn{2}{|c|}{ 3) Supercritical carbon dioxide (with heptane, in 1:1 ratio, T- $40^{\circ} \mathrm{C}, \mathrm{P}-8 \mathrm{MPa}$ ), \%: } \\
\hline Organic part of bituminous ground, including: & 99.9 \\
\hline \multicolumn{2}{|l|}{ Oil } \\
\hline (alcohol-benzene 1:1) RAS & $33.2^{*}$ \\
\hline
\end{tabular}

\footnotetext{
${ }^{*}$ After an additional sediment yield of RAS is reduced to $\sim 10 \%$.
} 
degree of branching, type of fused aromatic compounds. This can be explained by the fact that the $\mathrm{SC}^{\mathrm{CO}}$ reduces oil viscosity and improves the solubility of carbon dioxide, which contributes to the deposition of the asphalt-resinous substances.

\section{References}

[1] Samedova, F.I. (2014) The Application of Supercritical Fluids in Petroleum and Oil Fractions Refining. Baku. Elm, 105.

[2] Williams, D.F. (1981) Deasphalting of Heavy Oil Fractions. Chem. Eng. Sci., 11, 1769-1788.

[3] Kasumova, A.M. (2002) Supercritical Fluid Technology (Review). The Processes of Petrochemistry and Oil Refining, 3, 83-89.

[4] Paulaitis, M.E., Penninger, G.M.L., Gray, R.D. and Davidson Jr., P. (1983) Chemical Engineering at Supercritical Fluid Conditions. Ann. Arbor. Sci, 125-136.

[5] Reynolds, B.E., et al. (1990) Express Information. Oil Refining and Petrochemistry, $26,3$.

[6] Miralamov, G.F. (2001) Improving the Efficiency of the Gas Processing Plant. Baku. PhD Thesis, 150.

[7] Eckermann, B. and Vogelpohl, A. (1991) Express Information. Oil Refining, 2, 12.

[8] Yevdokimov, A.Yu., Fuks, I.G. and Bagdasarov, L.N. (1992) Lubricant Oils Based on Vegetable Oil and Animal Fats, Moscow. Ecochem, 120.

[9] Application 2790479, France.

[10] Ruth Raulaitis, M.E. (1999) Chem. Eng. In 21st Century. Seoul, August 16-19, 527.

[11] Dadashev, M.N. and Abdulagatov, I.M. (1993) Supercritical extraction in the processes of production and processing of oil, gas and coal. Chemistry and Technology of Fuels and Oils, 5, 31-36.

[12] Gumerov, F.M., Sabirzyanov, A.N. and Gumerova, G.I. (2007) Monograph: Sub- and Supercritical Fluids in Polymer Refining Processes. «FEN», Kazan, 334.

[13] Samedova, F.I., Kasumova, A.M., Rashidova, S.Yu. and Aliyeva, V.M. (2005) The Method of Deasphalting of Oil Residues. Patent i 20050089 Azerbaijan. B.I. 01.06.2005.

[14] Samedova, F.I., Kasumova, A.M., Rashidova, S.Yu. and Aliyeva, V.M. (2007) A New Method of Separating Asphaltenes from Crude Oil and Its Heavy Residues. Petrochemistry, 6, 432-434.

[15] Samedova, F.I., Rashidova, S.Yu., Kasumova, A.M. and Kuliyev, A.D. (2008) The Purification of Heavy Oil Residues and Their Asphaltene and Metals with Supercritical Fluid Extraction Using Carbon Dioxide. Supercritical Fluids: Theory and Practice, 3, 52-57.

[16] Samedova, F.I., Kasumova, A.M. and Rashidova, S.Yu. (2012) The Results of Studies of the Use of Supercritical Fluids in Oil Refining and Petrochemistry. Reports of ANAS, 4, 23.

[17] Samedova, F.I., Kasumova, A.M. and Rashidova, S.Yu. (2010) Supercritical Fluids in Petrochemistry and Oil Refining. Azerbaijan Oil Industry, 2, 50-54.

[18] Samedova, F.I., Kasumova, A.M., Rashidova, S.Yu. and Aliyeva, V.M. (2011) Supercritical Extraction of Oil and Its Heavy Residues Using SC- $\mathrm{CO}_{2}$ with Cosolvent. The Abstracts, IV Scientific and Technical Conference with International Participation "Supercritical Fluids: Fundamentals, Technology, Innovation", Listvyanka Settlement, Lake Baikal, 4-7 June 2011, 88-89.

[19] Samedova, F.I., Kasumova, A.M., Rashidova, S.Yu. and Bakhshesh, H.R. (2011) Dehydration and Desalting Using Supercritical Carbon Dioxide on ELOU-AVT Setting of Oil Refining Plant. Supercritical Fluids: Theory and Practice, 6, 13-19.

[20] Vitvitskaya, I.N. (1991) Deasphalting of Heavy Oils with Carbon Dioxide in the Pre- and Supercritical Condition. Oil Refining and Petrochemistry, 4, 14-18.

[21] Chernojukov, N.I. (1978) Technology of Oil and Gas Refining, Part 3, 420.

[22] Galimov, R.A., Abushayeva, V.V. and Krivonozhkin, L.B. (1991) The Influence of Pair Solvent to Deasphalting Processes and De-Oiling of Heavy Oils. Chemistry and Technology of Fuels and Oils, 11, 24-25.

[23] Klimenok, B.V. (1969) About Changing of the Solvent and Selectivity with the Changing of Temperature of the Extraction Separation. Chemistry and Technology of Fuels and Oils, 3, 3-5.

[24] Aliyev, V.S., Indyukov, N.M. and Rustamov, M.I. (1992) Termical Process of Oil Extraction from Bitumenous Stock. Chemistry and Technology of Fuels and Oils, 6, 10-12.

[25] Dadashev, M.N. and Stepanov, G.V. (2000) Supercritical Extraction in Oil Refining and Petrochemistry. Chemistry and Technology of Fuels and Oils, 1, 13-16. 
[26] Samedova, F.I., Najafova, G.N. and Aliyeva, V.M. (1995) The Direction of Processing of Azerbaijan Oil-Saturated Sands’ Organic Part. Azerbaijan Oil Industry, 5-6, 60-64.

[27] Samedova, F.I., Kuliyev, A.D., Gasanova, R.Z. and Aliyev, B.M. (2011) The Methods of Refining of Oil Extracted from Oil-Saturated Lands. World of Oil Products, 4, 12-14.

[28] Samedova, F.I., Gasanova, R.Z., Kuliyev, A.D. and Aliyev, B.M. (2013) The Application of Supercritical Extraction for Separating the Organic Part of Oil from Oil-Saturated Lands of Azerbaijan. The Abstracts, VII Scientific and Technical Conference with International Participation "Supercritical Fluids: Fundamentals, Technology, Innovation”, Zelenograd, 16-21 September 2013, 53. 